Tema: Aciaria Oxigênio

\title{
AVALIAÇÃO DE PRÁTICAS DE DESOXIDAÇÃO DO AÇO ABNT 1006 EM CONVERSOR LD PROCESSADO EM ESTAÇÃO DE BORBULHAMENTO*
}

\author{
Rafaela Pereira Batista ${ }^{1}$ \\ Antônio Augusto Martins ${ }^{2}$ \\ André Luiz Vasconcellos da Costa e Silva ${ }^{3}$
}

\begin{abstract}
Resumo
Aliar baixo custo à qualidade do aço é um desafio vital na siderurgia. Neste cenário, o conhecimento do efeito das variáveis de processo sobre o produto é uma ferramenta essencial. O vazamento do aço dos conversores LD é tradicionalmente dividido em vazamento acalmado e efervescente. Neste estudo avaliou-se o efeito de algumas das variáveis das práticas de vazamento de aços ABNT 1006 sobre composição química, rendimento de adições e limpeza interna. Esta classe de aço representou cerca de 35\% da produção da CSN em 2012. Através da comparação dos resultados industriais e avaliações teóricas, o estudo busca orientar os aciaristas sobre o efeito da escolha da pratica de vazamento e desoxidação na qualidade final e no custo de produção do aço em questão.
\end{abstract}

Palavras-chave: Conversor LD; Vazamento; Desoxidação por alumínio; Inclusões não-metálicas.

\section{A COMPARISON OF THE EFFECT OF DEOXIDATION PRACTICES ON SOME QUALITY CHARACTERISTICS OF CONVERTER SAE 1006 STEEL PROCESSED IN A RINSING STATION}

\begin{abstract}
Combining a reasonable cost and good quality is a vital challenge in steelmaking. It this framework, a good knowledge of the effect of the process variables is an essential tool. In converter steelmaking, two tapping practices are used with respect to deoxidation: rimmed and aluminum killed tapping. In this work the effect of some of the tapping practice variables on chemical composition, yield of added alloys and deoxidants as well as steel cleanness were evaluated for AISI 1006 steel. During 2012 , about $35 \%$ of CSN production was centered in this grade. By comparing industrial results and theoretical concepts, the work is aimed at guiding steelmakers on the effect of the choice of tapping and deoxidation practice both on steel cost and quality.
\end{abstract}

Keywords: BOF; Tapping; Aluminum deoxidation; Non-metallic inclusions.

\footnotetext{
Estudante, Engenharia Metalúrgica, Universidade Federal Fluminense, Volta Redonda, RJ, Brasil. Engenheiro Metalurgista, Companhia Siderúrgica Nacional, Volta Redonda, RJ, Brasil.

Engenheiro Metalurgista, MASc, PhD, Professor, EEIMVR, Universidade Federal Fluminense, Volta Redonda, RJ, Brasil.
}

* Contribuição técnica ao $45^{\circ}$ Seminário de Aciaria - Internacional, 25 a 28 de maio de 2014, Porto Alegre, RS, Brasil. 


\section{INTRODUÇÃO}

O vazamento do aço do conversor é normalmente dividido em duas formas, quanto ao nível de oxidação: efervescente e acalmado. O segundo se caracteriza pela adição de desoxidante no momento do vazamento. No caso de aços planos, majoritariamente, usa-se o alumínio, a fim de desoxidar o aço, formando alumina. Em contrapartida, nos aços vazados efervescentes, são adicionadas ligas a base de manganês durante o vazamento, antes de qualquer adição de alumínio.

A alumina formada deve ser transferida e absorvida pela escória da panela para garantir a boa limpeza interna do aço, isto é, um mínimo de inclusões não-metálicas presentes no aço acabado. Sendo assim o processo de desoxidação deve ser projetado não apenas para reduzir a quantidade de oxigênio dissolvido no aço, mas também para obter maior limpeza interna do aço [1-4].

Em princípio, como no processo de vazamento acalmado a adição de alumínio é feita durante o vazamento, o tempo disponível para que a alumina seja transportada e se incorpore a escória é relativamente longo. Adicionalmente, pode-se esperar uma significativa redução do FeO da escória passante do vazamento. O processo, no caso dos aços vazados efervescentes, é mais complexo: a adição de ferromanganês não é suficiente para uma efetiva desoxidação do aço, nem para reduzir significativamente o FeO presente na escória que passa do conversor para a panela. Somente após o vazamento, ocorre uma adição de alumínio, em fio, diretamente ao aço. A partir deste momento inicia-se o processo de eliminação da alumina formada nesta primeira adição de alumínio ao aço. Entretanto, sob estas condições, a escória passante do conversor praticamente não é desoxidada. Ao longo do processo, do final do vazamento do conversor até a máquina de lingotamento, o aço e a escória buscam o equilíbrio termodinâmico. Assim, o FeO da escória tende a reoxidar o aço. No caso do vazamento acalmado, em função da adição significativa de alumínio durante o vazamento, quando há grande agitação, o FeO da escória é, normalmente, reduzido, aproximando-se do equilíbrio com o aço, como mencionado acima.

O vazamento efervescente tem algumas aplicações importantes: (a) quando se deseja minimizar a absorção de nitrogênio durante o vazamento, este é o processo adequado, por aproveitar o efeito tenso-ativo do oxigênio; (b) quando o vazamento ocorre a temperatura considerada alta, o vazamento efervescente minimiza o efeito exotérmico da desoxidação, prevenindo o desgaste excessivo dos refratários e evitando a necessidade do uso de material refrigerante; (c) por fim, há argumentos de que o vazamento efervescente pode resultar em menor reversão de fósforo, associado ao equilíbrio:

$$
\underline{P}+\frac{5}{2} \underline{O}+\frac{3}{2} O^{-2} \leftrightarrow P O_{4}^{-3}
$$

Após o vazamento do conversor, é necessário ajustar a composição química e a temperatura para o lingotamento. Estas atividades são realizadas em processos de refino secundário. A CSN dispõe das seguintes opções de refino secundário: estação de borbulhamento de argônio; forno panela e desgaseificador RH. Em casos especiais, combinações dos processos podem ser empregadas. Dentre estas rotas foi avaliado apenas o aço produzido via estação de borbulhamento. A escolha se deveu a que esta é a rota mais simples de processamento, na CSN e, também, a de menor custo.

* Contribuição técnica ao 450 Seminário de Aciaria - Internacional, 25 a 28 de maio de 2014, Porto Alegre, RS, Brasil. 


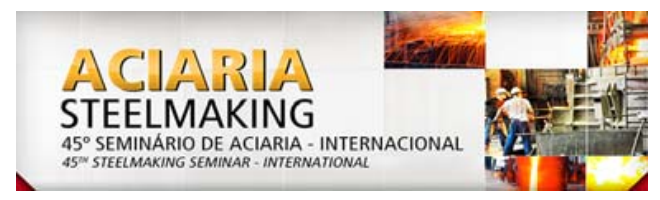

Pela expressiva importância na carteira da CSN, o aço ABNT 1006 foi escolhido como material em estudo. Tal grau, em 2012, representou cerca de $35 \%$ da produção da Companhia. Além disto, este aço é frequentemente empregado na produção de folhas metálicas. Por ser um produto de baixas espessuras, especificamente no caso de dupla redução até $0,14 \mathrm{~mm}$, a possibilidade de apresentar defeitos (furos e "riscos" sendo alguns dos mais comuns) associados a inclusões não-metálicas é apreciável.

\section{MATERIAIS E MÉTODOS}

Para avaliar a evolução da composição química, desoxidação e limpeza, buscou-se amostrar o banho metálico e a escória nas diversas etapas do fluxo produtivo, bem como o aço, já na forma de produto final. Após o tratamento na estação de borbulhamento, o aço foi amostrado com um amostrador de coquilha tipo lollypop e com amostrador TOS. A seguir, a escória foi amostrada através da imersão rápida de um vergalhão, sob o qual a escória se solidificou. Paralelamente foi medida a atividade do $\mathrm{FeO}$ na escória medida utilizando o sensor Celox Slac ${ }^{\circledR}$ [5]. A temperatura do aço, bem como a concentração de oxigênio dissolvido no aço ("ppm de oxigênio") foram medidos usando sensor Celox ${ }^{\circledR}$. A composição química das amostras de aço foram analisadas em espectrometria de emissão ótica e as amostras de escória foram analisadas através do espectrômetro de fluorescência de raios-X. A composição química das amostras TOS, para a determinação do teor de oxigênio total, por análise por combustão LECO. As amostras TOS foram analisadas no MEV. Aplicou-se método de extração de inclusão (norma ASTM E194-90), antes da observação no MEV.

\section{RESULTADOS E DISCUSSÃO}

\subsection{Análises Comparativas das Práticas de Vazamento}

\subsubsection{Escórias}

Com as análises de escória foi possível calcular, por termodinâmica computacional a atividade do FeO no final do tratamento na estação de borbulhamento (Figura 1). Verificou-se uma forte relação entre a atividade do $\mathrm{FeO}$ e a quantidade de alumina na escória. Considerando a reação:

$$
2 \mathrm{Al}+3 \mathrm{FeO} \leftrightarrow \mathrm{Al}_{2} \mathrm{O}_{3}+3 \mathrm{Fe}
$$

É razoável supor que a medida que a quantidade de desoxidante (Al) aumenta, forme-se mais alumina e a atividade do $\mathrm{FeO}$ na escória seja reduzida, uma vez que metal e escória se aproximam do equilíbrio ao final do tratamento. Observa-se, ainda, que, de forma geral, as corridas que seguiram a prática de vazamento acalmado tem escórias com menor atividade de FeO, como esperado.

* Contribuição técnica ao 45 Seminário de Aciaria - Internacional, 25 a 28 de maio de 2014, 

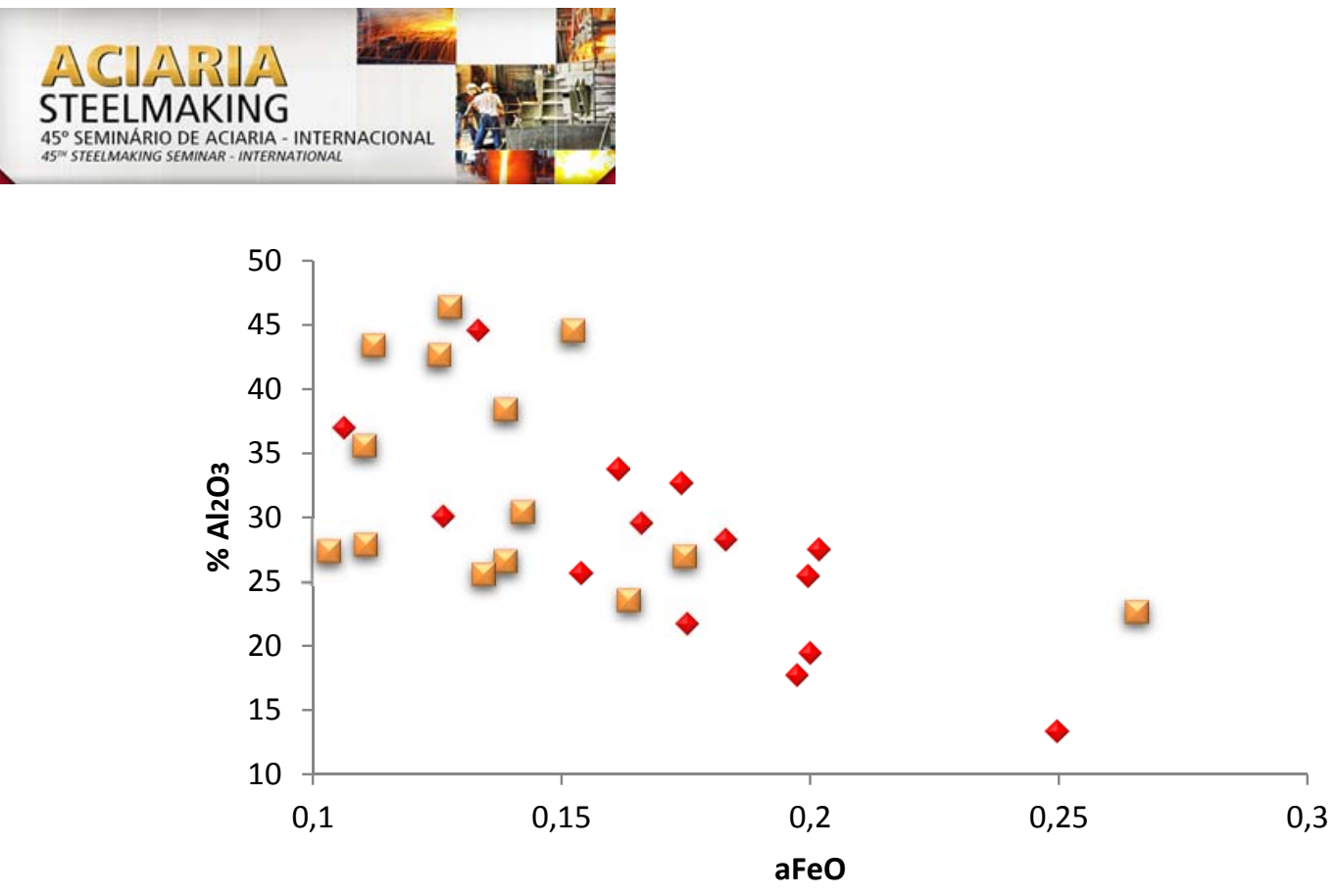

$\diamond$ Efervescente $\square$ Acalmado

Figura 1. Relação entre o teor de alumina e a atividade do FeO na escória ao final do tratamento na EB.

A análise estatística mostrou que aços vazados efervescentes apresentam, ao final do tratamento na estação de borbulhamento, maiores teores de oxigênio dissolvido que os acalmados (Figura 2a), assim como maiores atividades de FeO na escória (Figura 2b).

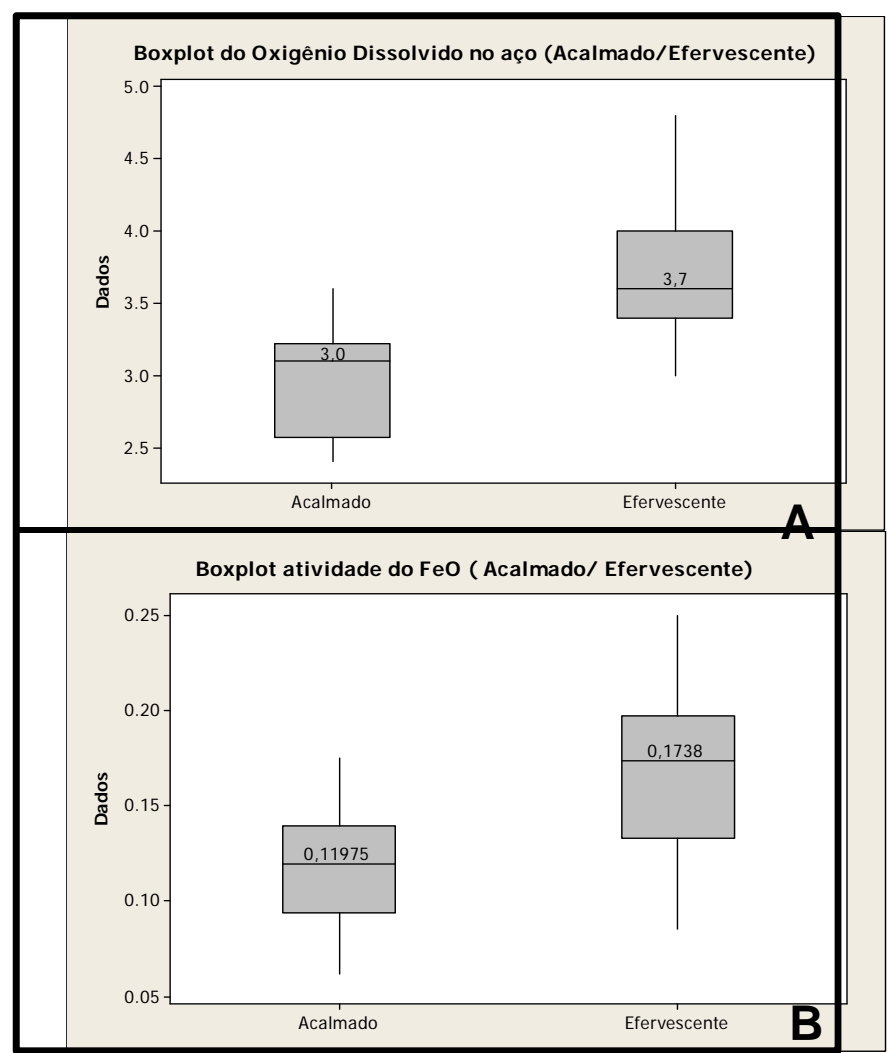

Figura 2. "Boxplots" de (a) do oxigênio dissolvido no aço e (b) atividade do FeO na escória após tratamento na estação de borbulhamento. Na Figura estão indicados máximos, mínimos, mediana e valores do primeiro e terceiro quartil para cada população.

* Contribuição técnica ao $45^{\circ}$ Seminário de Aciaria - Internacional, 25 a 28 de maio de 2014, Porto Alegre, RS, Brasil. 


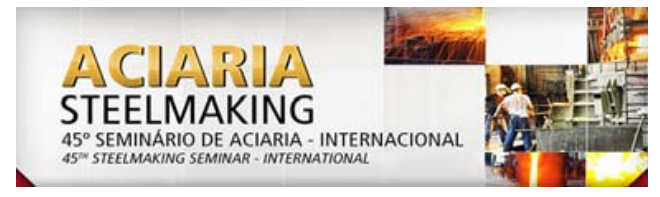

Para avaliar a distribuição do alumínio entre aço e escória nos dois processos foi adotado o seguinte procedimento: Calculou-se a massa de alumínio que não foi incorporado ao banho (peso de alumínio adicionado-peso de alumínio dissolvido no aço), esta variável foi denominada "Perda de Al para óxidos". Buscou-se correlacionar esta massa e o oxigênio a ser removido, por desoxidação, do aço. Esta variável foi denominada "Delta $\underline{\text { O }}$ " (teor de oxigênio de fim de sopro- teor de oxigênio no fim de tratamento na estação de borbulhamento). A análise das duas variáveis permitiu verificar que existe uma relação direta entre elas (Figura 3), como esperado pela conservação de massa do alumínio adicionado a panela. Ao examinar o comportamento de cada tipo de vazamento, entretanto, nota-se que nos aços acalmados há mais formação de alumina na escória, enquanto que, nos aços efervescentes, para uma mesma desoxidação do aço (delta O) a escória permanece mais oxidada. A partir do estudo de 1.620 corridas de aços ABNT 1006 processadas via estação de borbulhamento, conclui-se que o rendimento do alumínio, calculado como alumínio incorporado ao aço/alumínio adicionado, em corridas acalmadas gira em torno de 19\% enquanto em efervescentes 23\%. O restante é utilizado na redução de óxidos menos estáveis na escória e é oxidado ao ar, durante a adição [57].

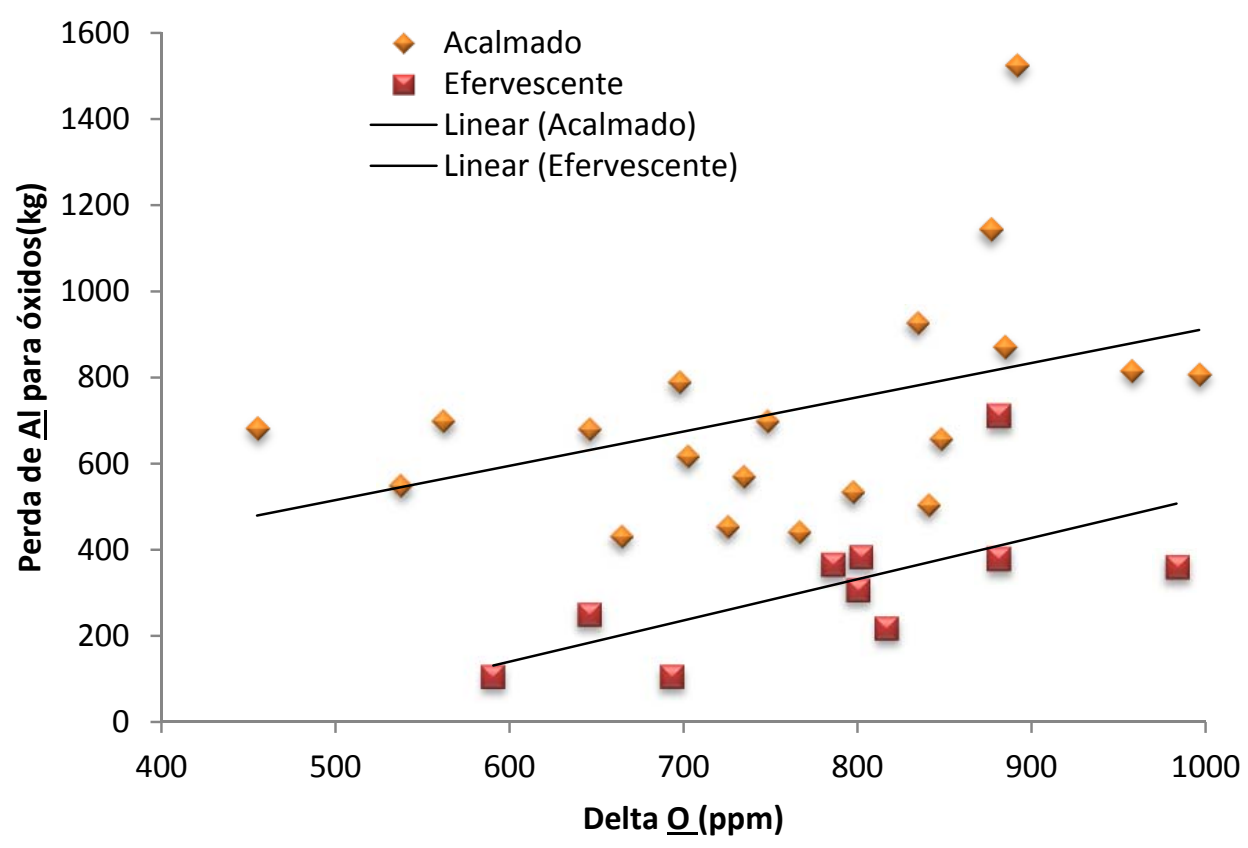

Figura 3. Massa de alumínio (kg) não absorvida pelo aço comparada a queda de oxigênio dissolvido no aço durante o vazamento até o final do tratamento na EB.

Idealmente, o teor de alumínio presente no distribuidor da máquina de lingotamento contínuo seria o mesmo encontrado na panela no momento da liberação desta da estação de borbulhamento. Todavia, a Figura 4 mostra que isto não ocorre. No intervalo entre a liberação da panela e a chegada a máquina de lingotamento, o teor de alumínio do aço diminui. Isto deve ocorrer por oxidação pelo ar ou pela escória. Observando-se os resultados da Figura 4, é evidente que os aços que seguem a prática acalmada perdem menos alumínio durante este intervalo de tempo do que os aços que seguem a prática efervescente $[9,10]$. Isto é consistente com a maior reoxidação do aço pelo $\mathrm{FeO}$ contido na escória, quando a prática efervescente é empregada.

* Contribuição técnica ao $45^{\circ}$ Seminário de Aciaria - Internacional, 25 a 28 de maio de 2014, 

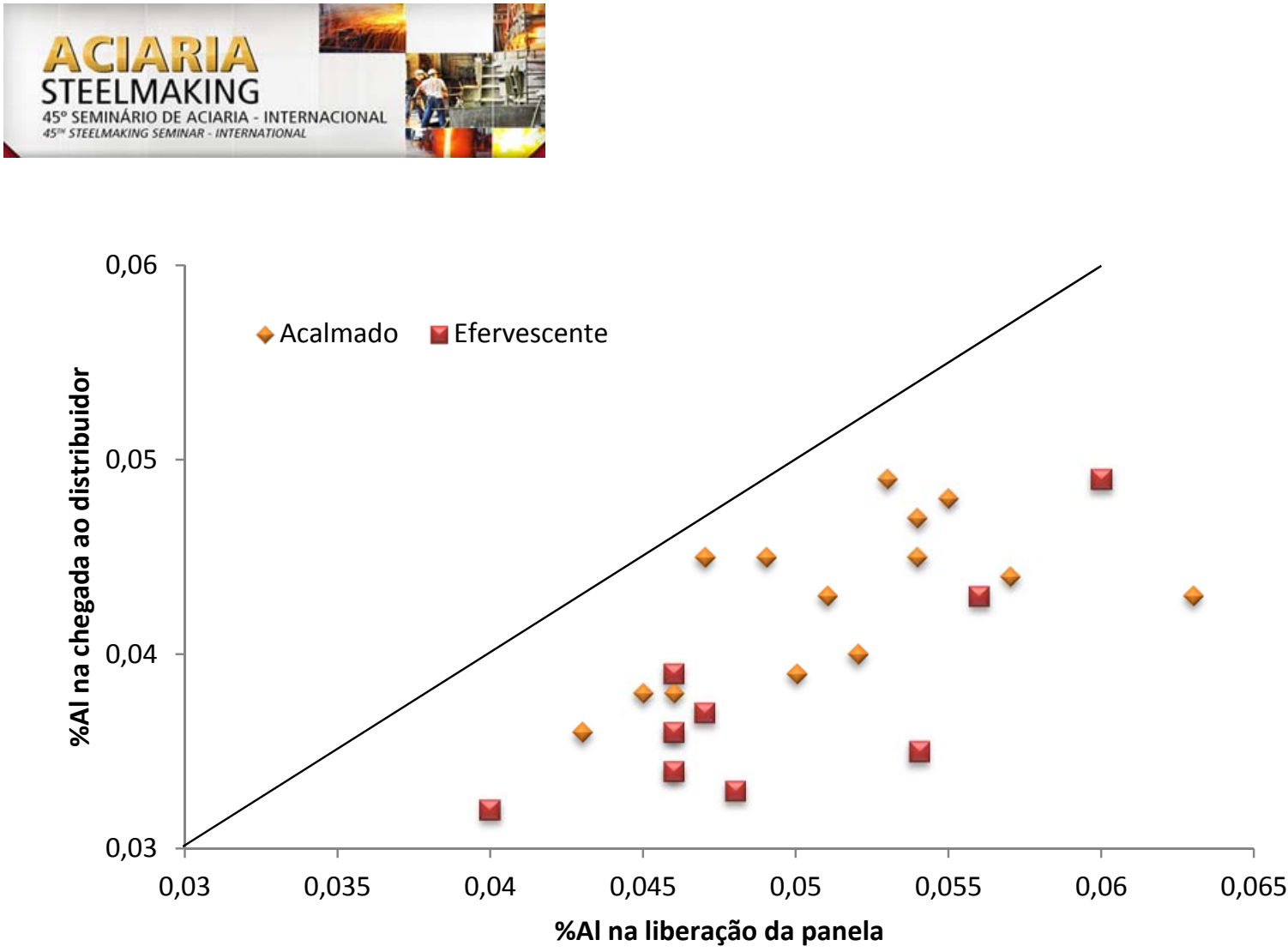

Figura 4. Comparação do teor de alumínio no aço durante o lingotamento e o no momento da liberação após tratamento na estação de borbulhamento.

A diferença na prática de desoxidação explica estas observações. A adição do alumínio durante o vazamento, na prática de vazamento acalmado faz com que tanto o aço quanto a escória passante do conversor sejam desoxidados. Ao chegar a estação de borbulhamento metal e escória tem potenciais de oxigênio relativamente próximos ao equilíbrio termodinâmico.

No vazamento na prática efervescente, só é adicionado alumínio ao banho na estação de borbulhamento, através da prática de injeção de fio. Neste caso, é possível reduzir consideravelmente o potencial de oxigênio do aço sem alterar, praticamente, o potencial de oxidação da escória.

A medida que ocorre agitação na estação de borbulhamento, entretanto, as condições para a busca do equilíbrio são favorecidas e o aço, desoxidado pelo alumínio injetado por fio, passa a desoxidar a escória. Isto resulta em queda no teor de alumínio do banho, com o tempo. Este processo continua ocorrendo mesmo depois da liberação da panela para o lingotamento continuo, como pode-se observar na Figura 4.

Os dados da variação do teor de alumínio entre a liberação na estação de borbulhamento e a chegada ao distribuidor, para as duas práticas, foram analisados estatisticamente. Através de um teste estatístico, concluiu-se que os dois grupos de dados são significantemente diferentes, o que permite afirmar que a queda do alumínio no aço neste intervalo depende significativamente da prática de vazamento, sendo mais acentuada em corridas vazadas efervescentes.

\subsection{Análises de Inclusões}

\subsubsection{Oxigênio total}

Comparou-se, também, o teor de oxigênio total de aços vazados pelas duas práticas, em amostras retiradas no distribuidor, (Figura 5). Como o teor de oxigênio total no aço é um método indireto usado amplamente para avaliar a limpidez do aço,

* Contribuição técnica ao $45^{\circ}$ Seminário de Aciaria - Internacional, 25 a 28 de maio de 2014, Porto Alegre, RS, Brasil. 


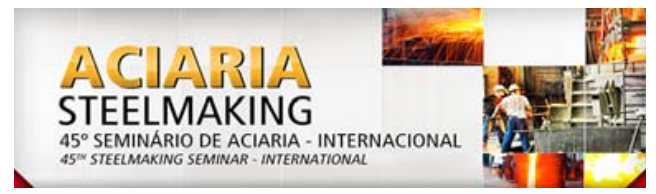

pode-se inferir pela Figura 6 que aços vazados acalmados apresentam maior limpeza interna do que os efervescentes [6-8].

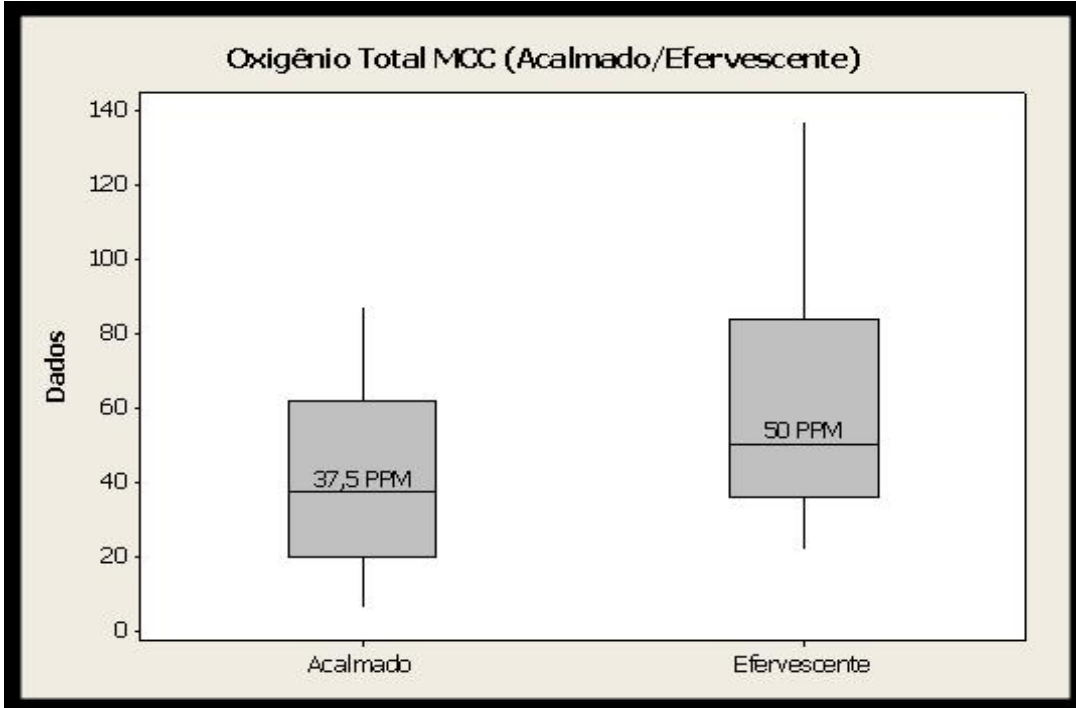

Figura 5. "Boxplot" comparativo do oxigênio total de amostra de aços acalmados e efervescentes coletadas durante o lingotamento contínuo. (ver Figura 2 para explicação dos dados do gráfico).

Amostras retiradas do distribuidor foram dissolvidas para extrair as inclusões de óxidos conforme a norma ASTM E194. Ao analisar a morfologia das inclusões de alumina presentes em aços vazados efervescentes, foram detectados principalmente inclusões de forma dendrítica (Figura 6a) e esférica (Figura 6b). Segundo $[6,10,11]$ estas morfologias são características de sistemas com elevada supersaturação em oxigênio (e alumínio). É provável que estas inclusões tenham sido formadas entre o fim de tratamento na estação de borbulhamento e até durante o lingotamento contínuo, devido a reoxidação localizada do banho, pela escória rica em FeO. Embora seja comum a formação da morfologia dendritica no início da desoxidação, esta é consideravelmente instável [11-14], devido à alta energia superficial associada. Seria pouco provável que uma dendrita de alumina formada na desoxidação no vazamento sobrevivesse, nesta forma, até o produto final, portanto.

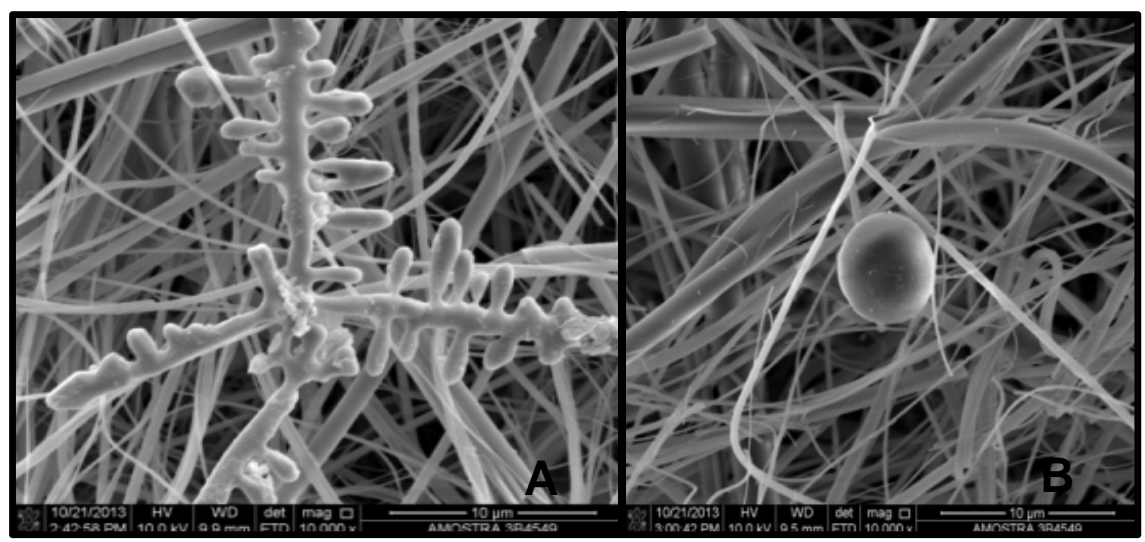

Figura 6. Inclusões não-metálicas encontrada em amostras de aços efervescentes. (a) Morfologia dendritica. (b) Morfologia esférica. (A rede de fibras longas sob as inclusões é o filtro empregado para reter o resíduo insolúvel conforme ASTM E194).

\footnotetext{
* Contribuição técnica ao 45 Seminário de Aciaria - Internacional, 25 a 28 de maio de 2014,
} 


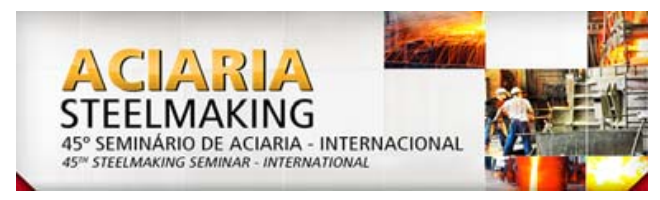

Em amostras de aços acalmados, notou-se maior incidência de inclusões facetadas (Figura 7). Esta morfologia caracteriza-se por apresentar baixa energia superficial $[6,14]$. É comum associar esta alteração morfológica à presença da inclusão no banho por um razoável tempo de processo. Assim, estas inclusões podem ser inclusões não removidas, provenientes da modificação de formas mais complexas formadas no início da desoxidação. No vazamento acalmado, a desoxidação se inicia mais cedo, de forma mais completa, o que é consistente com esta observação.

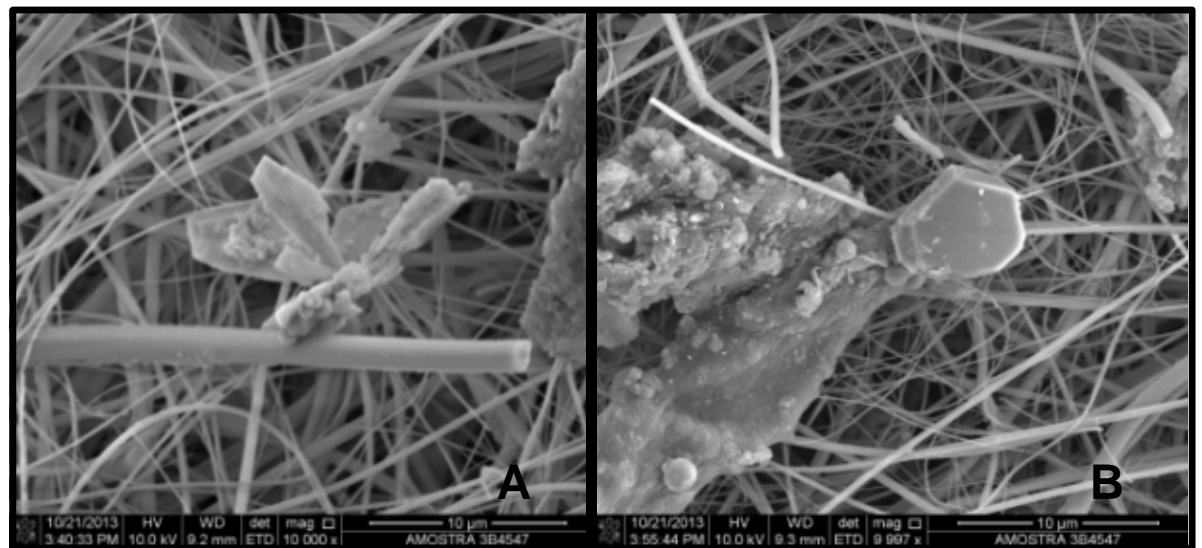

Figura 7. Inclusões não metálicas facetadas encontradas em amostras de aços acalmados (a rede de fibras longas sob as inclusões é o filtro empregado para reter o resíduo insolúvel conforme ASTM E194).

\subsection{Análises Comparativas das Práticas de Vazamento Através de Variáveis Operacionais}

\subsubsection{Consumo específico de ligas metálicas}

Para esta análise, considerou-se dados de 3.787 corridas do aço e rota em estudo, realizadas de janeiro a agosto de 2013. Para estas corridas, foi levantada a adição de ligas em todas as etapas do processo (vazamento, panela e estação de borbulhamento). Com base nos preços das ligas adquiridos pela CSN no mesmo período, calculou-se o custo específico de cada vazamento (R\$/t Aço). Observou-se que o vazamento efervescente resulta em um aumento de custo de 5,5\% em relação ao vazamento acalmado. Projetando anualmente, essa diferença representa cerca de $\mathrm{R} \$ 300.000,00$. É evidente que os valores de mercado das ferros-liga apresentam grande oscilação e o preço do alumínio tampouco é constante.

\subsubsection{Produtos fora de especificação}

Foram estudadas corridas dos aços ABNT 1006 que não se enquadraram na composição química especificada no período de janeiro de 2012 a agosto de 2013. Verificou-se que, dentre os produtos fora de especificação por baixos teores de manganês, alumínio ou carbono, aproximadamente $60 \%$ são vazados efervescentes. Por outro lado, cerca de $78 \%$ dos desvios da especificação por teores elevado de fósforo, carbono ou nitrogênio, ocorrem em corridas submetidas ao vazamento acalmado.

Apesar de indesejada, a produção de aços fora da especificação, é praticamente inevitável no processo, ou seja, produzir a totalidade das corridas dentro da especificação é relativamente difícil, em qualquer aciaria. Portanto é preciso se ter maneiras de minimizar as perdas associadas a este desvio. Uma solução usual e o desvio ou reaplicação do aço: procurar outras classificações que aceitem a

\footnotetext{
* Contribuição técnica ao 450 Seminário de Aciaria - Internacional, 25 a 28 de maio de 2014,
} Porto Alegre, RS, Brasil. 
composição química final do produto obtido. Focando nesta solução, verificou-se que, das corridas que não atenderam a especificação, $6 \%$ das acalmadas resultaram em sucateamento, enquanto nas efervescentes, este nível atingiu $20 \%$. Com base nos valores de produção da CSN em agosto de 2013, o sucateamento de uma placa de aço classificado pela norma ABNT 1006 representa prejuízo da ordem de $\mathrm{R} \$ 37.100,00$.

\subsubsection{Desvio de qualidade nas folhas de flandres}

Analisando-se os dados de produção de janeiro de 2012 a agosto de 2013 de folhas de flandres, verificou-se que $0,027 \%$ da produção total de corridas acalmadas do aço ABNT 1006 resultaram em anomalias devido à presença da alumina. Para corridas efervescentes, a incidência de anomalias devido a alumina foi de 0,066\% das corridas. Assim, vazamentos efervescentes, geraram aproximadamente duas vezes mais anomalias devido à alumina do que os acalmados. Ao focar apenas na rota estudada, ou seja, via estação de borbulhamento, a mesma tendência se manteve.

O padrão interno da CSN define que os defeitos presentes nas folhas de flandres não podem ultrapassam a $5 \%$ do comprimento total do produto. Caso esta norma não seja cumprida, a parte da bobina que contém os defeitos é sucateada. Valores de produção de agosto de 2013 mostram que o sucateamento gera prejuízo da ordem de $60 \%$ do custo da bobina.

\section{CONCLUSÕES}

O grande desafio atual das empresas é o balanço ideal entre custo e qualidade. A comparação entre o custo e a qualidade dos aços produzidos por vazamento efervescente e vazamento acalmado tem sido motivo de discussão em várias usinas. Assim, o presente estudo isolou, tanto quanto o possível, as variáveis que poderiam mascarar a comparação e selecionou todas as variáveis de custo e qualidade relevantes, no caso do produto escolhido. Comparando os resultados medidos e calculados por termodinâmica e observando-se os custos dos diversos insumos envolvidos ao longo de todo o processo, após o vazamento do conversor, observou-se que: o vazamento efervescente apresenta uma desoxidação incompleta do sistema. Enquanto o aço é, inicialmente desoxidado, a escória permanece muito oxidada e ao longo do restante do processamento age reoxidando o aço e alterando significativamente diversos parâmetros de qualidade.

Os aços vazados efervescente tem menor perda de alumínio para um mesmo teor final de oxigênio dissolvido no aço que em aços acalmados.

$\mathrm{Na}$ chegada e durante o lingotamento contínuo, observou-se menor estabilidade de parâmetros de qualidade do aço (composição, limpeza), em aços efervescente.

Uma comparação dos rendimentos metálicos considerando não apenas alumínio mas todos os elementos adicionais ao aço em questão indicou que o vazamento acalmando é mais favorável, economicamente. Além disto, os desvios de composição nos aços vazados acalmados são menos drásticos do que os provenientes de aços efervescentes.

Por fim, medida tanto do oxigênio total como da incidência de defeitos associados a alumina em folhas de flandres indicam que a limpeza interna do aço submetido ao vazamento acalmado é superior a do aço vazado efervescente. É recomendável, portanto, restringir o uso do vazamento efervescente aos casos em que efetivamente é vantajoso, como discutido.

* Contribuição técnica ao $45^{\circ}$ Seminário de Aciaria - Internacional, 25 a 28 de maio de 2014, 


\section{REFERÊNCIAS}

1 Goto H, Miyazawa K-I. Reoxidation behavior of molten steel in non-killed and Al-killed steel. ISIJ International. 1998;38(3):256-59.

2 Zhang L, Thomas BG. State of the art in evaluation and control of steel cleanliness. ISIJ International. 2003;43(3):271-91.

3 Turkdogan ET. Fundamentals of steelmaking. London: The Institute of Materials; 1996.

4 Fruehan RJ. The Making, shaping and treating of steel - Steelmaking and refining. $11^{\text {th }}$ ed. Pittsburg: AISE; 1998.

5 Coletti B, Smets S, Blanpain B, Wollants P, Plessers J, Vercruyssen C, et al. Measurement of ladle slag oxygen activity using electrochemical sensor. Ironmaking \& Steelmaking. 2003:30(3):217-22.

6 Dekkers R, Blanpain B, Wollants P, Haers F, Vercruyssen C, Gommers B. Non-metallic inclusions in aluminium killed steels. Ironmaking and Stellmaking. 2002;29(6):437-44.

7 Zhang L, Thomas BG. Inclusions in continuous casting of steel. In: XXIV National Steelmaking Symposium; 26th-28th Nov. 2003; Morelia, Mexico. pp.38-183.

8 Trojan PK. ASM Handbook - Casting. Vol. 15. Materials Park: ASM International; 1988.

9 Rasmussem P. Improvements to steel cleanliness at Dofasco's No. 2 melt shop. In: Iron and Steel Society. 77th Steelmaking Conference Proceedings; 1994; Chicago, EUA. Warrendale: ISS; 1994. p.219-24.

10 Steinmetz E, Lindenberg HU, Wahlers FJ. Morphologie der oxide und sulfide bei der desoxidation von eisenschmelzen mit mangan und silicium. Archiv fur das Eixenhuttenwesen. 1986;106(11):71-76.

11 Dekkers R, Blanpain B, Wollants P, Haers F, Gommers B, Vercruyssen C. A morphological comparasion between inclusion in aluminium killed steels and deposits in submerged entry nozzle. Steel Research. 2003;74(6):351-55.

12 Maes R. Celox applications in modern steelmaking - Application note. Nevada: Heraeus Electro-Nite; 2002. p.3.

13 Gaye $\mathrm{H}$. Inclusion formation in Steel - chapter 3. The Making, shaping and treating of steel. $11^{\text {th }}$ ed. Pittsburgh: AISE; 2003.

14 Van Ende M-A. Formation and morphology of non-metallic inclusions in aluminium killed steels (vorming en morfologie van niet-metallische insluitsels in aluminium gekalmeerd staal) [Doctoral thesis]. Lovaina: Universitè Catholique de Louvain; 2010.

* Contribuição técnica ao 45 Seminário de Aciaria - Internacional, 25 a 28 de maio de 2014, 